\title{
ADAPTASI PATROL BEKOH KERRENG RAMPAK PANDHALUNGAN DALAM AKTIVITAS MASYARAKAT JEMBER
}

\author{
Rizky Kumala Permadi \\ Jurusan Etnomusikologi, Fakultas Seni Pertunjukan \\ Institut Seni Indonesia Yogyakarta \\ Email: kiki.permadi123@gmail.com
}

\begin{abstract}
Abstrak
Pandhalungan adalah istilah untuk menyebut kebudayaan hasil akulturasi antara budaya Jawa Timuran (Surabaya), sebagian Banyuwangi dan budaya Madura. Akulturasi ini terjadi karena persebaran buruh tani dan buruh perkebunan pada masa kolonial belanda serta sejarah dari Tjakcraningratan Bangkalan yang kemudian membentuk suatu komunitas yang tersebar di Pesisir Selatan Jawa Timur bagian timur (Pasuruan, Probolinggo, Lumajang, Situbondo, Bondowoso, Jember dan sebagian Banyuwangi). Kabupaten Jember banyak terdapat grup patrol yang berdiri sampai saat ini, salah satunya adalah grup patrol Bekoh Kerreng Rampak Pandhalungan yang bermarkas di Desa Gebang, Kecamatan Patrang, Kabupaten Jember, Provinsi Jawa Timur. Kelompok patrol ini melakukan inovasi mengenai musik yang mereka bawakan dengan landasan sebagai masyarakat Pandhalungan dan musik patrol yang mereka sebut Rampak Pandhalungan. Metode yang dipakai dalam penelitian ini adalah metode kualitatif serta dibantu metode lain seperti, pendekatan etnomusikologi dan sosiologi untuk menganalisis dan membuat kesimpulan. Hasil penelitian menunjukkan bahwa Patrol Bekoh Kerreng mempunyai fungsi sebagai ungkapan ekspresi dan integrasi budaya.
\end{abstract}

Kata kunci : Fungsi, Patrol Bekoh Kerreng Rampak Pandhalungan, Masyarakat, Jember

\begin{abstract}
Pandhalungan is a term to refer to the culture resulting from acculturation between East Javanese culture (Surabaya), part of Banyuwangi and Madura culture. This acculturation happened because of the spread of farm laborers and plantation laborers in the Dutch colonial period and the history of Tjakcraningratan Bangkalan which later formed a community that was spread in the eastern part of South Coast of East Java (Pasuruan, Probolinggo, Lumajang, Situbondo, Bondowoso, Jember and part of Banyuwangi). There are many patrol groups in Jember that have been established to date, one of which is the Bekoh Kerreng Rampak Pandhalungan patrol group based in Gebang Village, Patrang District, Jember Regency, East Java Province. This patrol group is innovating about the music they bring with the foundation as the Pandhalungan community and patrol music which they call Rampak Pandhalungan.

The method used in this study is a qualitative method and assisted by other methods such as ethnomusicology and sociology approaches to analyze and make conclusions.

The results showed that Bekrol Kerreng Patrol has a function as an expression of cultural expression and integration.

Keywords: Function, Patrol Bekr Bekr Kerreng Rampak Pandhalungan, Community, Jember
\end{abstract}




\section{A. Pendahuluan}

Patrol adalah salah satu musik tradisi yang berkembang di wilayah bekas Karisidenan Besuki yang meliputi Probolinggo, Lumajang, Jember, Bondowoso dan Situbondo atau disebut pula wilayah Pandhalungan. Musik patrol adalah kesenian musik tradisional yang menggunakan alat musik sederhana yaitu kentongan. Instrumen melodis satu-satunya pada ansambel patrol adalah seruling bambu bernada slendro, namun sekarang lebih banyak menggunakan seruling bernada diatonis agar dapat menjangkau lagu-lagu khusus seperti lagu pop atau lagu dangdut. Hadirnya musik patrol sebagai identitas Kota Jember tidak terlepas dari komunitas Pandhalungan.

Pandhalungan adalah istilah untuk menyebut kebudayaan hasil akulturasi antara budaya Jawa Timuran (Surabaya), sebagian Banyuwangi dan budaya Madura. Akulturasi ini membentuk suatu komunitas yang tersebar di Pesisir Selatan Jawa Timur bagian timur (Pasuruan, Probolinggo, Lumajang, Situbondo, Bondowoso, Jember dan sebagian Banyuwangi). Hadirnya musik patrol ke Jawa Timur bagian timur itu sendiri tidak terlepas dari akulturasi kebudayaan Madura yang sangat kental. Kabupaten Jember memiliki banyak sekali sanggar ataupun grup patrol hingga saat ini, salah satunya adalah Grup Patrol Bekoh
Kerreng Rampak Pandhalungan salah satunya. Grup ini bermarkas di Desa Gebang, Kecamatan Patrang, Kabupaten Jember, Provinsi Jawa Timur. Bekoh Kerreng Rampak Pandhalungan berasal dari kata Bekoh yang dalam bahasa Madura berarti tembakau dan "Kerreng" yang dalam bahasa Madura berarti galak, maka jika digabungkan menjadi Bekoh Kerreng Rampak Pandhalungan berarti tembakau galak atau tembakau nyegrak. Grup Patrol ini memiliki tempat tersendiri bagi para penikmat musik patrol di Kabupaten Jember, Hal ini dikarenakan kelompok ini selalu berinovasi dalam setiap garapan musiknya dan menyuguhkan sesuatu yang berbeda diantara kelompok lain. Penambahan instrumen seperti kendhang Banyuwangi, kluncing Banyuwangi, kenong loro, selompret Ponorogo dan lain sebagainya. Nuansa musik yang disajikan juga memiliki ciri khas tersendiri, menghadirkan irama-irama Janger Banyuwangi pada beberapa garapan, menghadirkan irama-irama Suling Madura dalam beberapa garapan dan model tabuhan Obyokan dan Sampak Reog Ponorogo dalam beberapa garapannya dan sesekali juga mengusung konsep Ul-Dhaul Madura atau mobil goyang yang menjadi identitas Patrol Madura. Hal yang menarik dalam grup musik Patrol Bekoh Kerreng Rampak Pandhalungan ini adalah aransemen lagu 
mereka masih menggunakan idiom-idiom lokal kedaerahan seperti nuansa Banyuwangian, Ponoragan, Maduraan pada setiap repertoarnya.

Kebingungan akan identitas daerah yang terjadi dikarenakan Kabupaten Jember menjadi wilayah titik temu yang berbatasan langsung dengan wilayahwilayah yang notabene memiliki kebudayaan sendiri yang cukup kuat dan terjadi perdebatan atau spekulasi-spekulasi yang muncul dalam lingkup para seniman maupun budayawan Jember, kelompok Patrol Bekoh Kerreng Rampak Pandhalungan mengambil sikap mengenai musik yang mereka bawakan dengan landasan sebagai Masyarakat Pendhalungan dan musik patrol yang mereka sebut Rampak Pandhalungan. Melihat fenomena tersebut, muncul pertanyaan mengenai bagaimana bentuk musik yang disajikan oleh grup Patrol Bekoh Kerreng Rampak Pandhalungan.

\section{B. Metode Penelitian}

Zulkarnaen Moistofory dalam field Work menjelaskan bahwa dalam kasus etnomusikologi maka metode yang digunakan adalah deskripsi analitis sebuah metode yang menggambarkan mengenai peristiwa dan analisanya dalam konteks budaya, dimana pengumpulan data menggunakan wawancara, observasi dan dokumentasi.

\section{Pembahasan}

\section{Bentuk Penyajian Patrol Bekoh Kerreng Rampak Pandhalungan}

Bentuk penyajian musik patrol diklasifikasikan sebagai bentuk penyajian ansambel karena dimainkan secara bersama-sama. Intrumen yang dipakai pada saat penyajian adalah ansambel patrol berjumlah 6 buah, rebana berjumlah 4 buah, kentongan bambu berjumlah 4 buah, kendhang Banyuwangi, kempul, kenong loro, seruling, selompret dan vokal.

1. Aspek Musikal.

a. Instrumentasi

Instrumen yang digunakan grup Patrol Bekoh Kerreng Rampak Pandhalungan sebagian besar bersifat perkusif yang tergolong dalam kelompok Idiophone. Idiophone yang dipukul langsung, si pemain menggerakkan pukulan tersebut baik secara mekanik, atau dengan alat pemukul, atau secara key board atau dengan menarik tali elastis dan menimbulkan pukulan. Pokoknya si pemain bergerak baik dengan alat maupun tidak menimbulkan akibat pukulan, instrumennya sendiri memang disediakan untuk menerima pukulan (Sri Hendarto, 2011:5). Dalam buku organologi akustika menggunakan kode idiophones 111.2 dan membranophone 222.1. Instrumen melodis yang terdapat dalam ansambel Patrol hanya 
selompret Ponorogo dan seruling tergolong dalam kelompok aerophone.

b. Bentuk Musik

Lagu "kebyar-kebyar" merupakan lagu bertangga nada mayor, yang dimaksud lagu bertangga nada mayor adalah ketika sebuah lagu dimulai dengan tonika 1 (do) maka akan diakhiri dengan tonika 1 (do). Bentuk lagu "Kebyar-Kebyar" ciptaan Gombloh yang dibawakan pada saat itu merupakan bentuk lagu 2 bagian. Dengan penggambaran sebagai berikut, Bentuk lagu tersebut digambarkan A (kalimat tanya), A' (pengulangan harafiah kalimat A), B (kalimat jawab), C (kalimat baru) serta memasukan vokal ngelaik Banyuwangi, kejhung Madura dan pola ponoragan sebagai penggambaran 3 etnis pembentuk masyarakat Pandhalungan.

c. Struktur dan Pola Tabuhan

Berikut adalah struktur dan pola tabuhan yang sering muncul pada penyajian lagu "kebyar-kebyar" Bekoh Kerreng Rampak Pandhalungan :

1) Bass Patrol

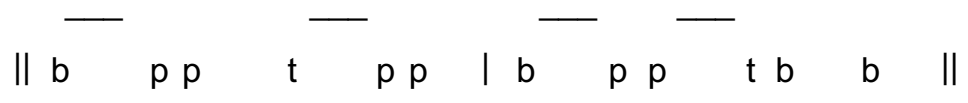

2) Konter Patrol

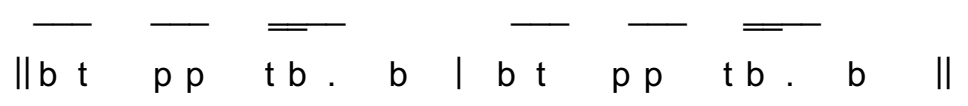

3) Remo Patrol

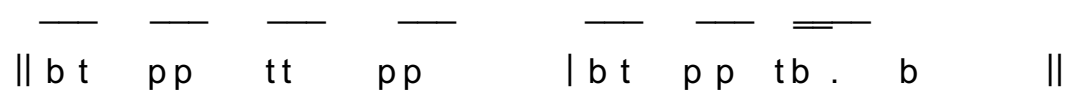

4) Kleter Patrol

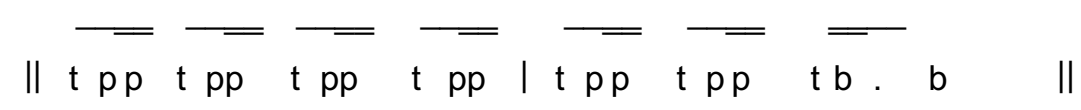

5) Tiktuk 1

$$
\begin{array}{lllllllllll}
\| & -t & & -t & . t & . t & \mid & . t & . t & . b & b
\end{array}
$$


6) Tiktuk 2

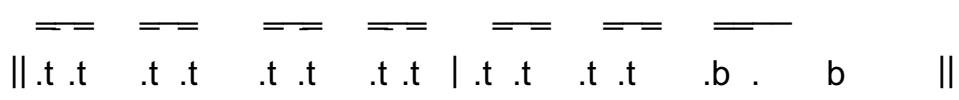

Instrumen Rebana terdiri dari 4 buah rebana dengan pola permainan yang berbedabeda. Berikut adalah pola motif rebana 1 sampai rebana 4 :

1) Rebana 1 dan Rebana 2

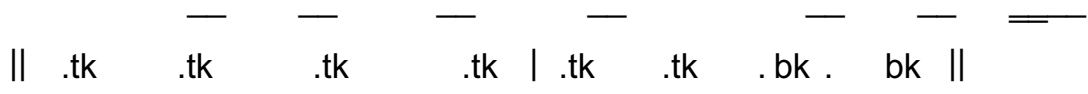

2) Rebana 3

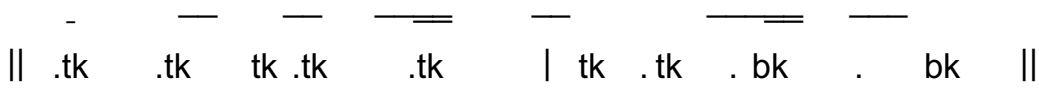

3) Rebana 4

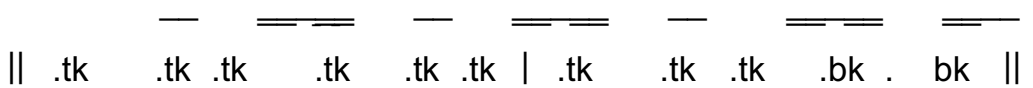

Instrumen Kempul dan Kenong, berikut adalah pola instrumen Kempul dan Kenong

1) Kenong

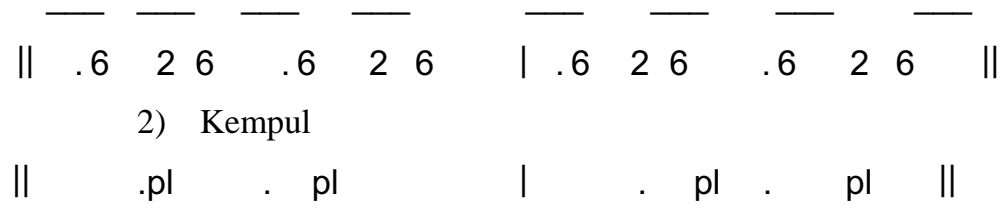

Instrumen kendhang Banyuwangi, berikut adalah pola instrument kendhang Banyuwangi

1) Kendhang Banyuwangi

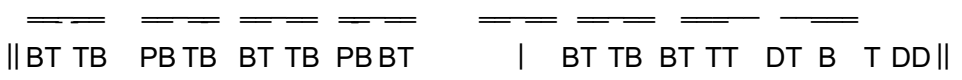

Disamping pola yang dijabarkan diatas, semua instrumen dalam garapan menyajikan pola unisound.

1) Pola unisound 1

$=\overline{\| b b b b}=\overline{t . b b} \quad \overline{b t} . \quad \mid b b b b$ t. bb $\overline{b t} \quad \bar{t}$ 


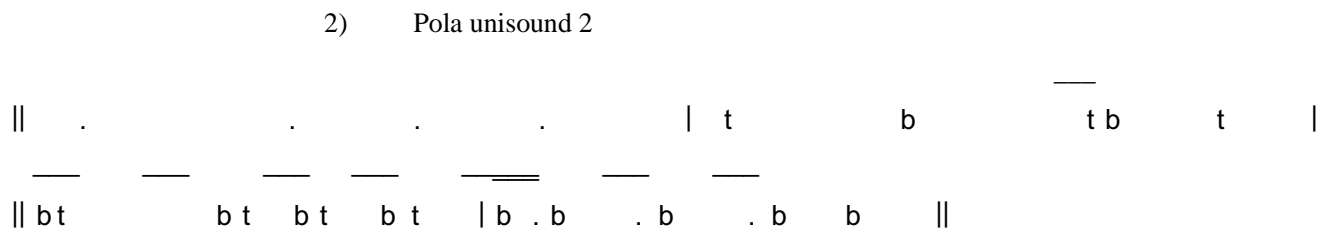

\section{Fungsi Patrol "Bekoh Kerreng Rampak Pendhalungan"}

Kegunaan dan fungsi merupakan masalah penting dalam etnomusikologi, dalam studi perilaku manusia. Hal ini masuk ke dalam konteks dalam etnomusikologi. Konteks adalah suasana, yaitu keadaan yang dibentuk oleh masyarakat pendukung musik tersebut (Nakagawa, 2002: 7). Untuk mengetahui kegunaan musik, peniliti harus berusaha menambah atau meningkatkan pengetahuan yang sesungguhnya secara langsung untuk memahami fungsi musik itu sendiri (Merriam, 1964: 22).

Fungsi musik dapat dibedakan menjadi dua, yaitu fungsi primer dan fungsi sekunder (RM. Soedarsono, 1999:170). Fungsi primer dari sebuah pertunjukan adalah apabila seni tersebut jelas siapa penikmatnya, hal ini berarti bahwa seni pertunjukan tersebut sebagai seni pertunjukan karena dipertunjukan kepada penikmat. Fungsi sekunder dari sebuah pertunjukan adalah apabila seni pertunjukan tersebut bertujuan bukan untuk sekedar dinikmati tetapi ada tujuan lain dibalik seni pertunjukan tersebut. Fungsi memperhatikan alasan dikerjakannya musik itu dan terutama maksud yang lebih luas musik itu dilaksanakan. Lebih penting lagi adalah adanya hubungan musik dengan anggota masyarakatnya sebagai ahli dalam mengikutsertakan musik atau kebudayaan tersebut.

Pendapat fungsi musik yang dikemukakan oleh beberapa ahli tentunya juga memiliki kajian yang berbeda-beda pula sesuai dengan zamannya masingmasing dan masyarakat pendukungnya. Alan P.Meriam menyebutkan bahwa fungsi musik dalam masyarakat memiliki sepuluh fungsi penting. Fungsi seni pertunjukan menurut Soedarsono juga dibagi menjadi tiga bagian dari fungsi seni pertunjukan yang sebelumnya terbagi menjadi dua, yaitu fungsi primer dan fungsi sekunder. Fungsi dibagi menjadi tiga adalah fungsi seni pertunjukan sebagai sarana ritual, seni atau pertunjukan berfungsi sebagai hiburan, seni atau pertunjukan berfungsi sebagai representasi estetis. Seni berfungsi sebagai sarana ritual adalah fungsi ritual seni yang berkembang pada nilai-nilai budaya agraris, 
serta masyarakat yang memeluk agama yang dalam kegiatan-kegiatan ibadahnya sangat melibatkan seni pertunjukan (RM. Soedarsono, 1999: 125). Seni pertunjukan sebagai hiburan pribadi. Seni atau pertunjukan yang berfungsi sebagai hiburan pribadi adalah seni yang harus melibatkan diri di dalam pertunjukan (art of participation), kenikmatan seorang penikmat adalah apabila ia bisa menari bersama dengan pasangan yang cocok, yang biasanya sebagai seorang penari wanita (RM. Soedarsono, 1999: 199). Seni pertunjukan yang berfungsi sebagai presentasi estetis. Presentasi estetis adalah sebuah seni kolektif, hingga penampilannya dibutuhkan dana yang tidak sedikit. Pada umumnya seni pertunjukan yang berfungsi sebagai presentasi estetis penyandang dana produksinya (production cost) adalah para pembeli karcis atau tiket (RM. Soedarsono, 1999:216). Pada dasarnya seni pertunjukan sebagai presentasi estetis sama dengan yang dijelaskan soedarsono pada buku "Seni Pertunjukan Indonesia di Era Globalisasi”, bedanya terletak pada tingkat estitetis yang menggunakan reward dan diselenggarakan secara detail untuk suguhan sajian pertunjukan atau tidak. Penulis menggunakan acuan buku "Metodologi Penelitian Seni Pertunjukan dan Seni Rupa"

Melalui pentas panggung yang kerap dilaksanakan oleh kelompok Patrol Bekoh Kerreng Rampak Pandhalungan dapat ditarik beberapa fungsi, khususnya pada saat panggung Festival Ramadhan Jawa Pos 2017.

\section{Fungsi Hiburan Pribadi}

Kenikmatan pelaku kesenian ketika melakukan pertunjukan di depan masyarakat umum dan juga sebaliknya bagaimana masyarakat umum ikut terhibur dengan adanya penampilan pertunjukan seni yang dilakukan oleh pelaku kesenian. Pelaku pertunjukan terhibur dan penikmat pertunjukan juga terhibur. Hal untuk menggambarkan fungsi hiburan pribadi yang bisa dinikmati oleh masyarakat atau penonton adalah ketika penonton atau masyarakat bisa ikut serta dalam irama yang ditampilkan dalam sebuah pertunjukan seni dan pelaku pertunjukan juga ikut terhibur akibat sinergi yang terjalin antara pelaku dan penikmat seni pertunjukan tersebut.

2. Fungsi Sebagai Presentasi Estetis

Seni pertunjukan adalah seni kolektif, sehingga kehadirannya diatas panggung memerlukan biaya yang tidak sedikit. Hal ini berkaitan dengan pertunjukan yang diadakan di atas panggung. Festival yang berlangsung di pastinya memiliki sponsor atau penyandang dana untuk sebuah pertunjukan tersebut. Seni pertunjukan sebagai presentasi estetis menurut Soedarsono dalam "Seni Pertunjukan Indonesia di Era Globalisasi" lebih berorientasi pada reward yang 
didapatkan setelah melakukan sajian yang menarik. Tidak menyangkal adanya jika pertunjukan yang menghadirkan kelompok Patrol Bekoh Kerreng Rampak Pandhalungan juga berfungsi dalam perputaran ekonomi kelompok tersebut. Hal ini juga bermaksud agar kesenian tersebut dapat berjalan dan terus berkembang serta mensejahterakan setiap anggotanya. Dalam Festival Ramadan Jawa Pos 2017 pada saat itu, reward yang diperoleh Bekoh Kerreng Rampak Pandhalungan adalah keluarnya kelompok patrol ini sebagai penyaji musik terbaik 1 . Fungsi Patrol Bekoh Kerreng Rampak Pendhalungan sebagai presentasi estetis pada saat Festival Ramadhan Jawa Pos ini lebih mengarah kepada hadiah yang diterima oleh kelompok karena sudah menyajikan penampilan yang menarik dan bagus sehingga pantas menurut saya untuk mendapat reward atau penghargaan atas proses sajian yang ditampilkan. Reward tersebut juga nantinya akan menjadi penopang untuk kelangsungan hidup kelompok itu sendiri dan akan menunjang keberlangsungan proses kreatif kesenian tersebut.

Selain fungsi primer yang dijabarkan diatas, musik patrol juga memiliki fungsi lain atau fungsi sekunder ketika para kelompok patrol yang ada melakukan arak-arakan untuk membangunkan orang sahur ketika bulan ramadan tiba. fungsi sekunder dari sebuah pertunjukan adalah apabila seni pertunjukan tersebut bertujuan bukan untuk sekedar dinikmati tetapi ada tujuan lain dibalik seni pertunjukan tersebut (RM. Soedarsono, 1999: 170) Arak-arakan atau pentas jalanan yang dimaksud adalah ketika kelompok musik patrol yang ada di Kabupaten Jember sepakat untuk berkumpul pada titik yang sudah ditentukan, biasanya mereka berkumpul di Alun-alun Kabupaten Jember atau di Double Way Universitas Jember. Dalam hal ini biasanya para kelompok patrol akan berkumpul dengan membawa instrumen mereka masing-masing sekitar pukul 23.00 wib dan akan dilanjutkan berkeliling Kabupaten Jember hingga pukul 03.00. Pemandangan seperti ini akan sering ditemui ketika bulan Ramadhan tiba, entah asal muasal kebiasaan ini bermula sejak kapan yang pasti kegiatan seperti ini sungguh memberikan nuansa yang sangat berbeda dari Kabupaten Jember dan secara tidak langsung bisa menjadi tradisi masyarakat Pendhalungan. Masyarakat Jember akan berdatangan satu persatu untuk melihat mereka memainkan musik patrol, antusiasme masyarakat dan waktu dimana para seniman patrol akan bertemu dengan pelaku kesenian patrol lainnya untuk saling menyapa dan menjalin keakraban sebagai sesama pelaku kesenian musik patrol, pertunjukan ini secara tidak 
langsung juga merupaka ajang kompetisi.

Dilihat dari kelengkapan sound, pola tabuhan yang paling menarik. Bukti dari adanya kompetisi adalah ketika grup itu didatangi oleh pengunjung, semakin ramai pengunjung yang mendatangi grup tersebut, maka menandakan bahwa grup tersebut lebih menarik daripada grup lain yang hadir. Pada pukul 01.00 wib mereka satu persatu akan keliling sambil memainkan alunan musik patrol menggunakan TOA pengeras suaradan rancak yang dimodifikasi agar bisa bermain musik sambil berjalan, ada juga yang bermain di atas truk. Rute yang mereka lalui biasanya berawal dari Double Way Universitas Jember, ke arah jalan kalimantan, lalu jalan mastrip, jalan PB Sudirman, tikungan lapas Kabupaten Jember dan berakhir di Alunalun Jember, begitu pula sebaliknya jika mereka berkumpul dari Alun-alun Kabupaten Jember maka berakhir di Double Way Universitas Jember, dengan sangat antusias masyarakat Jember akan menunggu mereka di pinggir-pinggir jalan sesuai rute mereka. Fungsi yang dijalankan pada sebuah pertunjukan seperti ini tentunya juga berbeda dengan ketika pertunjukan yang dilaksanakan pada sebuah panggung khusus. Panggung yang tersedia pada pertunjukan seperti ini adalah jalanan yang mereka sepakati dan penonton atau penikmatnya juga lebih merata, karena penonton tidak perlu datang ke tempat adanya pertunjukan, masyarakat cukup menanti di luar rumah dan menunggu mereka melewati rute-rute yang disepakati.

1. Sebagai Pengikat Solidaritas Kelompok Masyarakat

Musik patrol Jember tentunya tidak bisa dipisahkan dengan masyarakat Jember, karena merupakan bagian dari sistem sosial masyarakat setempat. Musik patrol merupakan alat pengikat solidaritas kelompok masyarakat. Hubungan antara kelompok musik dan anggota masyarakat sangat jelas berjalan erat. Hal ini dapat dilihat dari tidak adanya jarak antara pelaku kesenian dan penikmat kesenian jika konsep pertunjukan arak-arakan yang nantinya akan berkeliling untuk membangunkan orang sahur ini berlangsung. Dari kelompok Patrol Bekoh Kerreng Rampak Pandhalungan sendiri menjadi salah satu kelompok yang selalu hadir dalam acara seperti ini. Mereka merasakan tidak adanya jarak pemisah antara pelaku kesenian dan penikmat kesenian, bahkan mereka tidak segan-segan untuk membimbing masyarakat yang datang untuk sekedar mencoba menabuh patrol. Sistem pertunjukan seperti ini dirasa lebih efektif untuk memperkenalkan musik patrol kepada masyarakat Jember, dengan tujuan yang sama pula maka kelompokkelompok patrol yang turut serta tidak melihat keuntungan atau sisi komersilnya, semua berjalan karena sistem gotong 
royong, saling mendukung sesama kelompok patrol, bahkan bekal konsumsi mereka menyediakan sendiri hasil dari patungan anggota kelompoknya. Saat seperti ini mereka berpikir mengenai pengenalan musik patrol, menghibur masyarakat secara murni yang nantinya akan menumbuhkan persatuan antar kelompok, mempererat solidaritas antar kelompok lain dan masyarakat untuk saling menjaga tradisi yang sudah berjalan.

2. Fungsi Media Komunikasi Massa

Fungsi musik sebagai media komunikasi massa adalah ketika musik itu dapat menjadi pemberi simbol atau isyarat akan adanya sesuatu hal yang sudah menjadi kesepakatan bersama dalam masyarakat. Musik membuka peluang untuk memberi penyimbolan akan sesuatu yang sudah disepakati. Pada kegiatan ini, musik patrol menjadi media untuk melakukan komunikasi terhadap masyarakat sekitar bahwa ketika mereka sudah mulai berkeliling itu tandanya waktu sahur sudah tiba. Hal ini merupakan sebuah komunikasi satu arah dari pelaku musik patrol untuk masyarakat akan datangnya waktu sahur. Dalam hal ini, patrol Bhekoh Kerreng Rampak Pandhalungan ikut berperan mengkomunikasikan kepada masyarakat Jember akan datangnya waktu sahur.
Kebutuhan akan sebuah identitas menjadi begitu penting bagi sebuah komunitas karena sebuah komunitas memiliki salah satu sifat dasar yaitu adanya kesadaran yang muncul dalam sebuah komunitas akan suatu pembeda antara komunitas yang satu dengan yang lainnya. Pembeda tersebut pada akhirnya akan menjadi daya tarik komunitas lain ataupun orang-orang yang berada di luar komunitas. Identitas tidak hanya dipakai sebagai pembeda, tetapi juga membawa visi misi komunitas dan sebagai wahana pengenalan secara meluas mengenai konsep pemikiran yang dibawa oleh komunitas tersebut.

Kelompok Patrol Bekoh Kerreng Rampak Pandhalungan sadar betul akan kesenian yang perlu mereka tampilkan, tetapi dalam hal identitasnya Kelompok Patrol Bekoh Kerreng Rampak Pandhalungan memiliki visi misi untuk memperkenalkan kebudayaan Pandhalungan ke masyarakat luas. Pemilihan kata "Rampak Pandhalungan" menjadi point pertama yang mereka usung akan budaya Pendhalungan. Rampak berarti terdengar rapi, teratur, laras tentang bunyi-bunyian atau tetabuhan. Yang dimaksud sebagai rampak pendhalungan disini tetabuhan atau bunyi-bunyian yang instrumennya berasal dari keseniankesenian pembentuk budaya Pendhalungan. Patrol ini mencoba memberi warna tersendiri dalam setiap aransemen musik 
mereka dengan pemahaman pendhalungan secara intrumen, yaitu memasukan unsur Madura, Jawa dan Banyuwangi dalam setiap garapan mereka, serta pola-pola permainan yang mencangkup tiga unsur kesenian Madura, Jawa dan Banyuwangi sebagai gambaran Pendhalungan dalam bentuk kesenian khususnya musik. Hal ini tergambar dari aransemen atau garapan mereka yang memasukan pola-pola tradisi dari ke tiga kebudayaan tersebut menjadi satu komposisi musik yang mereka labeli sebagai Rampak Pandhalungan, secara instrumentasi kelompok ini juga menggunakan instrumen yang biasanya terdapat pada kesenian-kesenian Jawa, Madura dan Banyuwangi misalnya penggunaan Patrol yang mewakili Madura, Kendhang Banyuwangi, Kluncing, Seronen, Gong dan Saron yang mewakili Banyuwangi dan Jawa.

Pemilihan instrumen dalam kelompok ini didasari oleh perwakilan instrumen setiap etnis yang membentuk masyarakat Pendhalungan. Dalam aspek kostum yang mereka kenakan juga memiliki penggambaran masyarakat Pendhalungan, misalnya udheng yang mereka sebut sebagai udheng Pendhalungan atau ublang. udheng adalah destar, ikat kepala yang dipakai di kepala, bisa sebagai pengganti kopiah. Menurut kelompok Patrol Bekoh Kerreng Rampak Pandhalungan udheng yang mereka kenakan memiliki simbol Pendhalungan karena udheng tersebut didesain dengan percampuran pola atau bentuk odheng Madura, udheng Banyuwangi dan blangkon Jawa. Makna filosofis dari ketiganya mereka satukan menjadi udheng Pendhalungan yang bermakna bahwa hadirnya orang Pendhalungan merupakan percampuran dari tiga kebudayaan yang mendiami dan membentuk kebudayaan di Kabupaten Jember.

$$
\text { Reproduksi budaya hampir }
$$
merupakan proses yang perlu, bahkan bisa menjadi tujuan. Tindakan-tindakan lihai dari anggota-anggota kebudayaan yang ditunjukan dan dipuji secara terbuka oleh etnometodologi dalam detail etnografis yang rumit atau yang paling sering, dalam perbincangan, didedikasikan, meskipun tidak ditentukan, untuk memahami konteksnya dengan cara mereproduksi kondisi-kondisi dari kejadiannya sendiri secara reflektif (Christ Jenk, 2013: 187). Secara tidak langsung, Patrol Bekoh Kerreng Rampak Pandhalungan memproduksi budaya pandhalungan dari aspek kesenian dan telah mencoba memberikan penawaran titik tengah secara tidak langsung mengenai budaya pendhalungan yang mereka kenalkan melalui instrumentasi, kostum dan model garapan musik dalam setiap pagelaran maupun even-even yang mereka ikuti, hal tersebut didukung oleh pernyataan 
Susmiadi selaku kepala bagian kesenian

Dinas Pariwisata Kabupaten Jember yang mengatakan bahwa kelompok tersebut sering dipakai oleh dinas dalam penyambutan tamu dan acara-acara kabupaten karena dianggap mencerminkan kelokalan Jember dan Masyarakat Pendhalungan. Selain mendapat identitas kelompok, patrol Bekoh Kerreng Rampak Pendhalungan juga mencoba memulai melempar pehaman mengenai Masyarakat Pendhalungan dari segi kesenian.

\section{Simpulan}

Berdasarkan hasil penelitian di lapangan yang telah dianalisis, dapat disimpulkan bahwa bentuk penyajian Patrol Bekoh Kerreng Rampak Pandhalungan dikategorikan dalam bentuk penyajian musik ansambel karena dimainkan secara bersama-sama dengan memasukkan instrumen dan pola-pola permainan dari 3

1. Bagian 1 memasukan musik etnis Banyuwangi

2. Bagian 2 berisi tentang lagu "kebyarkebyar" yang sudah dibawakan secara Pandhalungan

3. Bagian 3 memasukan unsur dari etnis Madura dan Ponoragan. etnis pembentuk masyarakat Pandhalungan.

Contoh lagu "kebyar-kebyar" yang diaransemen menjadi 3 bagian :

Tinjauan lain dari Patrol Bekoh Kerreng Rampak Pandhalungan dalam masyarakat juga memiliki fungsi primer yaitu fungsi hiburan, fungsi presentasi estetis dsn fungsi sekunder, diantaranya fungsi pengikat solidaritas kelompok masyarakat dan media komunikasi massa. Hadirnya musik patrol dirasakan ketika bulan ramadan tiba.

Usaha pembentukan identitas yang dilakukan oleh grup Patrol Bekoh Kerreng Rampak Pandhalungan adalah dengan memasukan unsur-unsur musikal ketiga etnis tersebut dan bentuk udheng, sehingga diharapkan mendapat pengakuan oleh masyarakat Jember dan pemerintah Kabupaten Jember

\section{Daftar Pustaka}

Abdullah Irwan. 2015. Kontruksi dan Reproduksi Kebudayaan.

Yogyakarta: Pustaka Pelajar.

Hadi Setio. 2016. Asal-usul Pandhalungan. Jember: Salam Nusantara.

Hendarto Sri. 2011. Organologi dan Akustika I\&II. Bandung: CV. Lubuk Agung.

Jenks Chris. 2013. Culture Studi Kebudayaan. Yogyakarta: Pustaka Pelajar

Ma'Arif, Samsul. 2015. The History Of Madura. Yogyakarta: PT Araska.

Merriam Alan P. 1964. The Antropology of Music. Northwestern University Press. 
Moeleong, Lexy J. 2017. Metodologi Penelitian Kualitatif. Bandung: PT Remaja Rosdakarya.

Nakagawa, Shin. 2000. Musik dan Kosmos: Sebuah Pengantar Etnomusikologi. Yogyakarta: Yayasan Obor Indonesia.

Nettl, Bruno. 2012. Teori dan Metode Dalam Etnomusikologi. Jayapura: Jayapura Center Of Music.

Prier, Karl-Edmund SJ. 1996. Ilmu Bentuk Musik. Yogyakarta: Pusat Musik Liturgi.
Soedarsono, R.M. 2001. Metodologi Penelitian Seni Pertunjukan dan Seni Rupa. Yogyakarta: Masyarakat Seni Pertunjukan Indonesia.

Soedarsono, R.M. 2002. Seni Pertunjukan Indonesia di Era Globalisasi. Yogyakarta: Gadjah Mada University Press.

Zoebazary, Ilham. 2017. Orang Pendhalungan Penganyam Kebudayaan di Tapal Kuda. Jember: Paguyuban Pendhalungan Jember. 